\title{
Emotional labour and vicarious traumatization among
}

\section{nurses}

\author{
C Patricia Mazzotta ${ }^{1,2 *}$ \\ ${ }^{1}$ School of Community and Health Studies, Centennial College, Toronto, Canada \\ ${ }^{2}$ School of Nursing, University of Victoria, Victoria, British Columbia, Canada
}

\section{Introduction}

The essence of nursing, most would agree is captured by a nurses' ability to care for another human being. This is a privilege many cannot even fathom because nurses are invited to share a person's most intimate and vulnerable moments, nurse bears witness to the beginning of life and the end of it. Within this reality, a nurse holds deep within the heart compassion, courage and a capacity to care. For this reason, many would say nursing is a woman's domain and woman's work, essentially because women are believed to be emotional beings, put on this earth to nurture and mother those in need [1]. Gender stereotypes have significantly influenced the nursing profession. Historically, nursing was deemed a profession for women because cultural norms and traditional thought viewed nursing as women's work, it was assumed women were emotional labourers for the sick [2]. However, nursing continues to evolve. What was once considered a womens' profession no longer applies today. Men are demonstrating that they can contribute to the profession and discipline and are valuable to nursing. The purpose of this paper is to explore emotional labour and vicarious traumatization from nurses' perspective. Using Hochschild's theory of emotional labour, I will discuss the impact emotional labour has on the profession and its effects of vicarious traumatization on nurses because of the everyday challenges facing point of care nurses but more importantly, how can nurses (re)engage in practice.

An assumption is that as nurses we possess the ability to withstand tremendous emotional demands and continue to perform our duties while keeping a façade between our public and private identities [3]. Emotional labour is a part of our work in nursing. We frequently witness human suffering and experience emotional turmoil, but we suppress our feelings and emotions for the welfare of our clients. Emotional labour then "requires one to induce or suppress feelings in order to sustain the outward countenance that produces the proper state of mind in others...emotional labour is sold for a wage and therefore has exchange value" [4]. However, the problem with emotional labour arises when nurses can no longer cope with the effects of emotional and psychological aspects of daily work. When nurses witness constant human suffering and emotional turmoil, we may potentially experience vicarious traumatization [5]. Essentially, vicarious traumatization results from witnessing continuous human suffering and traumatic experiences, thus, leaving the nurse involved with residual and lasting effects [6]. Admittedly, emotional labour erects barriers and masks the effects of vicarious traumatization among nurses. Often we recognize these effects when we distance ourselves from our clients and colleagues, and we find ourselves detaching our feelings and emotions to what we overtly portray [4].
As I ponder the meaning of 'the art of nursing,' I am disturbed by the reality that, as point of care nurses, we are losing our ability to care using a holistic lens. Our past nursing leaders have made tremendous contributions to the nursing profession, for instance, Rufaida Bent Saad Al-Islamiya [7], Mary Grant-Seacole [8], Florence Nightingale [9], Margaret Higgins Sanger [10,11], Lavina Lloyd Dock, Mary Adelaide Nutting [12] and Martha Franklin [13] to name a few. These women made it their mission to evolve nursing education, to bring a voice to nurses and to care for the sick regardless of the adversities they faced because of gender, lack of equipment and limited training. These nurses embraced their identity of a nurse through mindful reflection and were sure in their comprehension of what constituted caring [14]. Nurses gave of themselves willingly without reservation regardless of circumstances, and part of their identity of being a nurse was that of an emotional labourer.

Many of us are nurses because our ability to care, our education, training and the beauty found deep within our healing hands. Yet, the complexity of caring for the sick has changed, and I find myself wondering when we will find the time to practise the art of nursing and return to the early teachings where the client was our priority. Unfortunately, we are unknowingly being shifted from practicing the aesthetics of nursing to practicing within an empirically based business model of care [15] in which the sick client is now a consumer, and akin to a customer receiving services. Thus, nursing care becomes a commodity [14] without regard for the consequences on point of care nurses.

Today the perception of nurses is that we are knowledgeable consumers and producers of research [9], we are autonomous in our care, we have the knowledge to question physician's orders when necessary, and to advocate for our clients. As much as I welcome these changes to our profession, it seems we remain in the shadows of a business model of care because of the increased client acuity, advances in technology, organizational demands [15], and the cloud of financial budgets and strategic business plans. The focus remains on treating the disease and before getting the client out of the hospital and into the community to meet inancial constraints on hospitals. Therefore, the business model implemented by many organizations in order to

Correspondence to: C. Patricia Mazzotta 755 Morningside Avenue, Centennial College, Toronto, Ontario, M1C 4Z4, Canada, Tel: 1416-289-5000; 1 289-9286682; E-mail: pmazzott@uvic.ca

Received: January 29, 2016; Accepted: February 26, 2016; Published: March 02,2016 
meet budgetary demands is hindering our ability to care for clients holistically. I wonder if these organizations have considered the impact a business model has on healthcare and the future of nurses and nursing. The reality is that when we are forced to work under stressful conditions such as, inadequate staffing, increased client acuity, and increased workload, we respond by suppressing our emotions and putting on a mask in order to meet our clients' needs to keep clients satisfied. We do this regardless of the implications for our own wellbeing.

Emotional labour is a major aspect of the work we do every shift, this is the part of our work that is invisible. After all, how can we quantify the emotional work that we do and the humanness of our actions when we are carrying out acts that cannot be subjectively or objectively defined, especially on units where witnessing human suffering is a norm. Tensions arise when we are asked to prioritize organizational demands before client care [16]. For example, a colleague explained how she is expected to demonstrate, in her annual self-evaluation, how she contributed to the hospital meeting its strategic goals. The reality is that nurses are struggling to stay afloat meeting the needs of the client and their significant other(s) while continuing to smile. Majomi, Brown, and Crawford [17] and Montgomery, Panagopolou, de Wildt, and Meenks [18], acknowledge that increased demands on nurses today along with the diminished importance given to emotional labour is detrimental to nurses. The result is nurse burnout, inauthenticity of self, and encouraging a façade whereby nurses are actors playing a role for the day [19]. Sometimes it seems we are marionettes, required to perform on a daily basis to meet organizational needs, client satisfaction, and strategic business plans. Sadly, we seem to be going backward in time where nurses follow in the shadows.

\section{Hochschild's theory of emotional labour}

If one is to understand Hochschild's theory of emotional labour, we must first contemplate the meaning of 'emotion.' According to MerriamWebster (2014), emotion is defined as the combined "subjective experience, expressive behaviour, and neurochemical activity" in the brain. William James [20] posits emotion is the mind's perception of physiological conditions that result from external influences. Similarly, Hochschild [4] suggests that emotions elicit a physiological reaction because of our conscious or unconscious reactions that require us to take action. The manner by which we respond to these emotions depends on prior knowledge, experience, and societal influences [4]. Another factor to consider is how we manage our feelings and what types of emotions are triggered when we do so.

Through expression of our emotions and contextual factors influencing our lives, we are able to determine how we choose to display our emotions, whether we will publicly display or keep them to ourselves. From this perspective, Hochschild introduces the concept of emotional management whereby the types of emotion experienced by an individual [nurses] are attributed to values and norms, or what [4] refers to as feeling rules. Feeling rules are the manner by which people comprehend their emotions, what they are feeling, what it means to feel these emotions and how they should express them appropriately [4]. Emotional management is learned through socialization that reflects social and cultural factors; Hochschild emphasises that emotional work is comprised of a public and private domain. The private domain consists of an individual's home, family and friends [4] and the public domain, in this case, is capitalist societies that take advantage of private emotional work for commercial gain [21].

Thus, emotional labour is the effect of the organization controlling all aspects of emotional work. Nurses are emotional labourers, simply because it is part of being a nurse. However, I would argue that because emotional labour is inherent in the work that we do and how we conduct ourselves as point of care nurses, it is easy for employers to take nurses work for granted. Organizational leaders are often more concerned with customer (client) satisfaction that has measureable outcomes and not the interpersonal skills demonstrated by nurses that cannot be measured. Therefore, the result is that we suppress our emotions and feelings in order to ensure the client is satisfied. Hochschild [4] states "feelings are made to serve external ends that are remote, the more the managed heart becomes not me" [22]. This quote emphasizes the importance of keeping our feelings and emotions genuine, if we do not, we risk losing ourselves in an objective world where humanness no longer matters. I believe we risk becoming imposters and donning a mask in order to fulfill a role that is not becoming of the nurses we are.

Since, emotional labour demands that employees either publicly display their emotions or keep them hidden in order to bring others a sense of wellbeing; a correct assumption then, would be that nurses are masters of emotional labour because they are able to manage their emotions depending on the situation at hand. For example, while working a night shift in the emergency department, I recall caring for a 48-year-old woman in the acute room; she was diagnosed with ovarian cancer with metastasis. Her husband and three teenage daughters brought her in because of their inability to control her pain at home. I remember she apologized to me because her family would not leave her side. I just smiled and said it was okay, because I could work around them. It would be hours before I finally got her pain under control. All the while, thinking how stoic she was. I remember checking in on her and noticing that her three daughters were wrapped around their mother, while her husband held her hand. I called for a hospital bed to be brought down knowing she would be admitted to the Palliative Care Unit. At approximately 0400 hours, I observed her family leave her cubicle so I took the opportunity to reassess her pain and move her into the hospital bed. I noticed her gown was wet from perspiration, so I proceeded to wash her, change her gown and assisting her into the hospital bed. I had the privilege of hearing about her family while rubbing her back. She began to cry and tell me about her fear of dying, not being alive to see her daughters graduate, get married or that she would never experience being a grandmother. I sat at the side of her bed and just held her hand while my heart broke for this woman.

I remember walking out her cubicle with a lump in my throat and tears in my eyes that threatened to overflow while walking towards the next cubicle in order to assess a new client with a smile on my face. In reality, all I wanted was have the opportunity to deal with my emotions before I had to care for someone new. It is not surprising to me that nurses are required to become jugglers for a multitude of emotions attributed to observing human suffering, thus leading to vicarious traumatization [23]. Unfortunately, the term debriefing is not a new concept to nurses or in nursing, but admittedly, because of the contextual factors influencing our care and time with clients debriefing is often overlooked.

Presently, emotional labour cannot be measured and nurses are not acknowledged for providing this care to their clients, essentially because we are paid to manage our emotions and perform a service [24]. However, there are key differences between Hochschild's theory and its relation to nursing. First, the major differences is that emotional labour is embedded within our care, because of the relational aspect of our work, the emphasis is not on profit but on holistic nursing care [14]. Ultimately, organizations require satisfied clients (customers), however, as nurses we must adhere to practice standards, nursing 
ethics, and answer to our regulatory body. In other words, we have a professional and moral obligation not only to ensure we provide excellent client care, but also ensuring we implement multiple ways of knowing in order to achieve best client outcomes.

Second, emotional labour is an important aspect of the collaborative and therapeutic relationship between nurse/client-interactive relational processes [14]. This point is different from the research done originally with flight attendants, because our relationship with clients is fluid, it cannot be one sided and linear because we play multiple roles in helping our clients reach their optimum health. Meaning that without trust, a relationship between the nurse and client cannot be established, and in Hochschild's work, the emphasis was on the airline's profit and passenger satisfaction.

Third, emotional labour is required because when clients are in a vulnerable position, nurses play a vital role as advocates and ensuring client's rights are protected [14]. I believe that that nurses should not hold power over a client; the client and their significant other(s) should be the ones driving their plan of care. Lastly, emotional labour requires exchange of emotions [14]. For me, this is a crucial aspect of our work, because we are emotional beings and share in so many intimate moments of a client's life. I cannot fathom not experiencing the sharing and exchanging of emotions. Unfortunately, the continued exposure to human suffering and the emotional work puts us in a predicament, because of our ability to care deeply for others, juggling work demands, emotions, and our own private struggles makes us vulnerable to the negative aspects of our profession.

\section{The challenges of emotional labour}

Nurses are facing new challenges working for organizations where business models are the norm and customer (client) satisfaction reigns supreme despite stressors affecting nurses. Gray $[25,26]$ suggests that leaders have a responsibility to assess emotional labour in health care settings and implement strategies to help nurses regulate their emotions. This includes providing nurses the ability to assess and manage their own emotions as well as those of their client(s), but more important, to assess the manner in which nurses handle difficult elements of client care [26]. The danger of not acknowledging the depth of emotions experienced by nurses every shift is the risk of losing the 'art of nursing,' and more importantly, of becoming actors that face critical situations without feeling and empathy.

\section{Losing sight of what it means to care}

A clinical example that comes to my mind is, while working in the acute room of a level one emergency/trauma unit, I assumed care of a middle age man who had been struck by a car while riding his bicycle to work. A man, who hours before had been full of life, a husband, father, son and brother, he had made a conscious decision not to wear his helmet. He was intubated upon arrival to the trauma room-there was nothing to be done to save his life, his prognosis-poor. I commenced care and carried out my initial assessment, I noticed he was still covered in blood, glass, and dirt. I knew I did not have much time to clean him up before his wife and daughter arrived on the unit. His family did not know the extent of his injuries nor the decision facing them upon arrival to the emergency department. They would have to decide if they would withdraw care, keep him on life support or would they consent to organ donation. I could only imagine the difficult task that lay before them. I asked a fellow nurse to help me clean him up, her response: "why, there is nothing we can do for him." I was shocked by her reply; however, I realize that we all deal with grief in different ways. I explained to my colleague that although we sometimes become desensitized to the environment, the blood, and the tubes, we must remember the client is still someone's husband, father and a human being who needed to be cared for with dignity. She walked away telling me she was going to "see what was going on in the trauma room." I cleaned this man up alone, talking to him and explaining everything I was doing. I grieved for this man, his family, but most of all I grieved for this young nurse a recent graduate in her sixth month of practice [27].

\section{(Re) engaging as nurses}

Nurses often use detachment as a means of coping with their stress and anxiety, however, Smith [28] reiterates that nurses have the ability through training and experience to accept and recognize their feelings in order to be fully engaged in a therapeutic relationship with their client [1]. I concur with Smith's observations because witnessing human suffering is not easy, but we journey alongside our client's in their moment of need. By focusing on the client's needs and the role we play, one crucial aspect is overlooked, that is, how do we educate and bring awareness to nurses on the concept of emotional labour.

Short [6] posits the importance of nurses acknowledging the gift we have in our hands by openly acknowledging the work we do, the emotions and feelings we experience because of the difference we make. My question then is how can this young nurse and many like her understand what it means to possess such a gift. If nurses cannot begin to comprehend the meaning and purpose of what it means to be a nurse, then how do we help our colleagues gain insight and reflect on their actions? How do we help them grow personally, professionally but more important, acknowledge and accept the moral and ethical obligations that come with being a nurse who practises holistically?

The complexity of nursing work requires nurses to be emotionally connected with their client(s), after all this is the most difficult and rewarding aspect of our profession. Through reflection, nurses open themselves to practising in a relational and genuine approach in our interactions with clients. Reflective practice enables us to acknowledge our strengths, areas for improvement but illuminates our feelings and emotions that we otherwise would have remained hidden. This means that we must be willing to give a little bit of ourselves, but in the end, the difference we make is priceless. Gray [26] suggests that reflection is an integral part of emotional labour, by analyzing the situation we are able to problem solve, and share our experiences with others. This helps support emotional labour in nursing because it establishes the interpersonal relations between a client, their significant other, and the nurse. What organizational leaders do not comprehend is that emotional labour is vital to the maintenance and running of health services [26]. The reality is that despite the physical, emotional, and psychological exhaustion of nurses, nurses perceive emotional labour to be the heart of the profession, because it integrates not only the art of nursing but also the heart of it.

Emotional labour needs to be acknowledged by organizational and government leaders because it is crucial that nurses be supported in dealing with the emotions they face on a daily basis. The lack of recognition of emotional labour and the invisible effects of suppressing our emotions and feelings in nursing should concern organizational leaders and educators because of the impact that it has on nurses, causing them to leave the profession. Prince Waterhouse Cooper's Health Research Institute (2007) reports, "the average nurse turnover rate in hospitals was $8.4 \%$, and the average voluntary turnover rate for first-year nurses was $27.1 \%$ " [15]. What this means to me is that if a business model is dictating healthcare, then special attention needs 
to be paid to the emotional state of nurses because retention and recruitment will affect client satisfaction. Reich [15] asks two very important questions, "How can we change the environment to one where nurses are empowered rather than discouraged?" and "How can we create a healing and nurturing environment within the complexity of the professional life?" (p. 89). As I reflect on these questions, I propose that acknowledging the emotional work that nurses do on a daily basis is instrumental to feeling. Moreover, acknowledging that nurses feel angst when they witness continuous human suffering, not because we are women but because we are human illuminates the burden of the emotional and psychological aspects of our work. Nurses often experience emotional turmoil every shift, thus contributing to physiological symptomology such as tachycardia, insomnia, gastrointestinal problems, anxiety, depression and avoidance [29,30]. Therefore, it is imperative that resources are in place to help nurses cope and to thrive within the context of a profession founded on the essence of caring.

In conclusion, emotional labour is a part of nurses' work; however, there are implications to practise when nurses are not able to practise holistically. As business models are introduced into healthcare systems, organizational leaders must not forget the nurses. Nurses are emotional labourers; meaning that when nurses are supported in their work and resources are in place to enable nurses to care for their clients and themselves, the results are that client satisfaction is increased and positive health outcomes are evident. Resources need to be readily available to help illuminate the invisibility of vicarious traumatization among nurses because of the suppression of emotions. Furthermore, organizational and government leaders must begin to acknowledge the relational and interpersonal work that nurses contribute in sustaining healthcare regardless if a measurement tool exists or not.

\section{Acknowledgements}

The author acknowledges the assistance provided by Rita Schreiber, DNS, RN, Professor Emeritus School of Nursing University of Victoria, B.C, Canada for her feedback on this manuscript.

\section{References}

1. Henderson A (2001) Emotional labor and nursing: an under-appreciated aspect of caring work. Nurs Inq 8: 130-138. [Crossref]

2. James N (1989) Emotional labour: Skill and work in the social regulation of feeling. Berkeley, CA: University of California Press.

3. O’Brien M (1994) The managed heart revisited: Health and social control. The Editorial Board of The Sociological Review. Cambridge, MA: Blackwell Publishers.

4. Hochschild AR (1983) The Managed Heart: Commercialization of Human Feeling. Berkeley, CA, University of California Press.

5. Little S (2002) Vicarious traumatisation. Emerg Nurse 10: 27-30. [Crossref]

6. Short SM (2012) Vicarious traumatization and the call for universal precautions. NENA Outlook 35: 25-29.
7. Meleis A (2011) On the way to theoretical nursing: Stages and milestones. In Theoretical nursing: development and progress ( $5^{\text {th }}$ edtn) (pp. 59-81). New York: Springer.

8. Salih S (1857/2005) Wonderful adventures of Mrs. Seacole in many lands. New York, NY: Penguin Books Limited.

9. Burns N, Grove SK (2013) Understanding nursing research. Building an evidencebased practice. In Understanding nursing research: Building an evidence-based practice ( $5^{\text {th }}$ edtn) (pp. 2-31). Maryland Heights, MO: Elsevier Saunders.

10. Selanders LC (1998) The power of environmental adaptation. Florence Nightingale's original theory for nursing practice. J Holist Nurs 16: 247-263. [Crossref]

11. Sanger M (1922) The pivot of civilization. New York, NY: Bretano's Publishers.

12. Nutting MA, Dock LL (1907-1012) A history of nursing: The evolution of nursing systems from the earliest times to the foundation of the first England and American training Schools for nurses. New York, NY: G. P. Putmam's Sons.

13. Massey GE (1933) The National Association of Graduate Colored Nurses. The American Journal of Nursing 33: 534-536.

14. Theodosius C (2008) Understanding emotional labour in nursing. A theoretical approach. In: Emotional labour in healthcare. The unmanaged heart of nursing (11-28). New York, NY: Routledge.

15. Reich J (2010) Reflections: Healing our environments. The Journal of Holistic Nursing 28: 89-91.

16. James N (1992) Care $=$ organisation + physical labour + emotional labour. Sociology of Health and Illness 14: 488-509.

17. Majomi P, Brown B, Crawford P (2003) Sacrificing the personal to the professional: community mental health nurses. J Adv Nurs 42: 527-538. [Crossref]

18. Montgomery A, Panagopolou E, de Wildt M, Meenks E (2006) Work-family interference, emotional labour and burnout. Journal of Managerial Psychology 2: 3651.

19. Bolton S (2001) Changing faces: Nurses as emotional jugglers. Sociology of Health and Illness 23: 85-100.

20. James W (1884) What is emotion? Mind 9: 188-205.

21. Theodosius C (2006) Recovering from emotion management. Sociology 40: 893-910.

22. Ehrlich R (1984) The managed heart: Commercialization of human feelings by Arlie Hochschild. Theory and Society 13: 731-736.

23. Hooper C, Craig J, Janvrin DR, Wetsel MA, Reimels E (2010) Compassion satisfaction, Burnout, and compassion fatigue among emergency nurses compared with nurses in other selected inpatient specialties. Journal of Emergency Nursing 36: 420-427.

24. Steinberg R, Figart DM (1999) Emotional labour since the managed heart. Annals of the American Academy of Political and Social Science 561: 8-26.

25. Gray B, Smith P (2009) Emotional labour and the clinical settings of nursing care: the perspectives of nurses in East London. Nurse Educ Pract 9: 253-261. [Crossref]

26. Gray B (2010) Emotional labour, gender and professional stereotypes of emotional and physical contact, and personal perspectives on the emotional labour of nursing. Journal of Gender Studies 19: 349-360.

27. Mazzotta CP (2013) Viewpoint-NURS 602. Unpublished manuscript. University of Victoria, BC.

28. Smith P (1992) The emotional labour of nursing. Macmillan Education: London

29. Lombardo B, Eyre C (2011) Compassion fatigue: a nurse's primer. Online J Issues Nurs 16: 3. [Crossref]

30. Tweedie DJ (2014) Case study 7. Compiled aha moments in enzyme kinetics: authors' experiences. Methods Mol Biol 1113: 513-519. [Crossref]

Copyright: (C2016 C. Patricia Mazzotta. This is an open-access article distributed under the terms of the Creative Commons Attribution License, which permits unrestricted use, distribution, and reproduction in any medium, provided the original author and source are credited. 